\title{
Development of huperzine A and B for treatment of Alzheimer's disease
}

\author{
Donglu Bai
}

\author{
Shanghai Institute of Materia Medica, Chinese Academy of Sciences, \\ 555 Zuchongzhi Road, Shanghai, 201203, China
}

\begin{abstract}
Recent studies have proved that huperzine A (HupA) possesses different pharmacological actions other than the inhibition of hydrolysis of ACh. These noncholinergic roles, for instance, the antagonist effect on NMDA receptor, the protection of neuronal cells against $\beta$-amyloid, free radicals, and hypoxia-ischemia-induced injury, could be important too in Alzheimer's disease (AD) treatment. The therapeutic effects of HupA are probably based on a multitarget mechanism. By targeting dual active sites of AChE, a series of bis- and bifunctional HupB compounds with various lengths of tether were designed, synthesized, and tested for the inhibition and selectivity of AChE. The most potent bis-HupB compound exhibited increase by three orders of magnitude in AChE inhibition and two orders of magnitude in selectivity for AChE than its parent HupB.
\end{abstract}

Keywords: acetylcholinesterase inhibitors; butyrocholinesterase inhibitors; huperzine A; huperzine B; Alzheimer's disease; dimers.

\section{INTRODUCTION}

Millions of years of plant evolution have led to the development of many secondary metabolites with various and unique chemical structures that scientists have not even thought of. So far, less than $20 \%$ of all plant species have been evaluated chemically or biologically. Therefore, medicinal plants remain an important source in the search for new leads, new chemical entities of drugs, and new mechanisms of drug action as well [1,2]. On earth, there are at least 250000 species of higher plants. They contain a much greater diversity of bioactive compounds than any chemical library. Many more useful drugs will be found in the plant kingdom if the research projects are conducted in a systematic and logical manner [3].

Alzheimer's disease (AD) is the most common form of dementia and one of the major diseases affecting elderly people. The cholinergic enhancement strategy has now been one of the major efforts to pharmacologically palliate the cognitive symptoms. To date, the most effective approach has been the use of acetylcholinesterase (AChE) inhibitors, such as tacrine, donepezil, and rivastigmine. In China, huperzine A (HupA) is the first-choice drug in the treatment of AD.

*Pure Appl. Chem. 79, 467-823 (2007). An issue of reviews and research papers based on lectures presented at the $25^{\text {th }}$ International Symposium on Chemistry of Natural Products (ISCNP-25) and $5^{\text {th }}$ International Conference on Biodiversity (ICOB-5), held jointly in Kyoto, Japan, 23-28 July 2006, on the theme of natural products. 


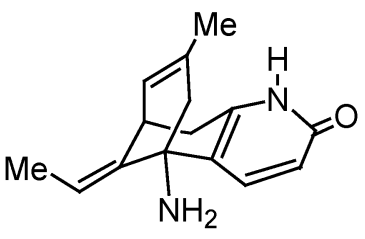

Huperzine A

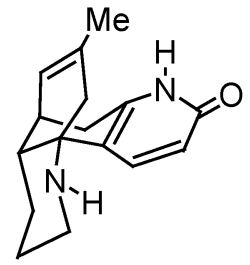

Huperzine B

\section{HUPERZINE A}

The Lycopodium alkaloid HupA (1) was isolated from a Chinese folk medicine, Huperzia serrata (Thunb.) Trev., by Liu and his coworker in 1986 [4-6]. This club moss has been used in China for the treatment of contusion, strain, swelling, and schizophrenia. The total alkaloids from this plant could alleviate the symptom of myasthenia gravis.

\section{Occurrence of HupA}

(-)-HupA occurs in several plant families such as Huperziaceae, Lycopodiaceae, and Selaginella. From 1995 to 2001, an investigation of the natural resources of the Huperziaceae family in China was carried out to catalog the occurrence, general distribution, and abundance of various species [7-9]. In the Huperziaceae family, there are two genera, huperzia and phlegmariurus. The yields of HupA in dried herb of Huperzia serrata range from 0.0047 to $0.025 \%$ depending on the collecting seasons and growing regions. In this genus, herteriana, ovatifolia, and serrata species have higher yields of HupA than others. In Phlegmariurus genus, all of the 11 species investigated have much higher contents of HupA than Huperzia plants. The highest contents of HupA were found in carinatus and mingcheensis species [7].

In H. serrata whole plant, the yield of HupA varied by $33 \%$ throughout the year. Samples collected in October had the highest yield $(97.6 \mu \mathrm{g} / \mathrm{g})$, whereas the lowest yield $(64.0 \mu \mathrm{g} / \mathrm{g})$ was observed in late winter through spring. The yield of HupA also varied dramatically by tissue. The highest yield was found in leaves $(111.8 \mu \mathrm{g} / \mathrm{g}$ ), whereas the roots and sporangia had much lower levels (24.9 and 37.7 $\mu \mathrm{g} / \mathrm{g}$, respectively). Most recently, Ma et al. have succeeded in propagating Phlegmariurus squarrosus. The cultured plants may provide a new source of HupA [7].

\section{Pharmacological and clinical studies of HupA}

The anticholinesterase activities of HupA were evaluated in vivo, and significant inhibitions of AChE were observed in the cortex, hippocampus, and striatum in rats. There clearly is a dose-dependent inhibition of AChE in the brain region by HupA. In contrast to donepezil and tacrine, HupA has a higher oral bioavailability $[10,11]$.

Studies using microdialysis technique in rats showed that HupA elevated dose-dependently the level of ACh in cortex. (Fig. 1, results shown as mean $\pm \mathrm{SEM}$. $* \mathrm{P}<0.05$, $* * \mathrm{P}<0.01$ vs. baseline.) The time course of cortical AChE inhibition by HupA is positively correlated with the increase of ACh. (Fig. 1, \#P $<0.05$, \#\# < 0.01 vs. saline control.) According to the doses of inhibitors, HupA was 8and 2 -fold more potent than donepezil and rivastigmine, respectively, in increasing cortical ACh levels with a longer-lasting effect [12].

The improving effect of HupA in memory deficits is more potent on working memory than on reference memory compared with donepezil and tacrine. This effect may be beneficial in AD treatment, because the cognitive deficits in $\mathrm{AD}$ patients are severe for the memory of recent events [13-15]. 


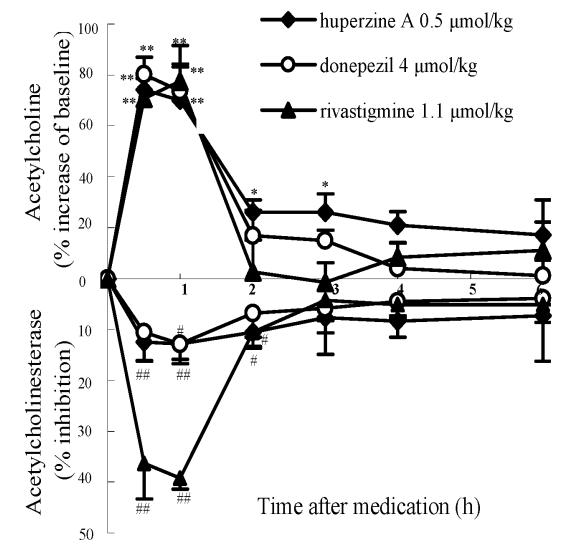

Fig. 1 Comparative effects of HupA, donepezil, and rivastigmine on the cortex ACh levels and AChE activity in rats after ip injection.

To study the efficacy of HupA on memory and learning performance of students, HupA has been tested in 34 pairs of middle school students complaining of memory inadequacy by using double-blind and matched-pair method. The results of this study exhibited that HupA markedly improved the memory function of adolescent students [11,17].

Recent pharmacological studies have proved that HupA possesses different bioactivities other than the inhibition of hydrolysis of ACh. These noncholinergic effects-including the antagonistic effect on NMDA receptor, the protection of neuronal cells against cytotoxicity and apoptosis induced by $\beta$-amyloid, free radicals, and hypoxia-ischemia - could also be important in AD treatment [20]. Interestingly, the neuroprotective effect of HupA is not correlated with its AChE inhibition, suggesting that the therapeutic effect of HupA may be exerted via a multitarget mechanism $[11,18]$.

\section{Synthetic studies of HupA}

Because of the unique bioactivity and low yields in plants, several groups have devoted intensive efforts to the chemical synthesis of HupA. It possesses the rigid bicyclo [3.3.1]nonene skeleton and fused pyridone ring. The retrosynthetic analysis of this molecule is shown in Scheme 1.

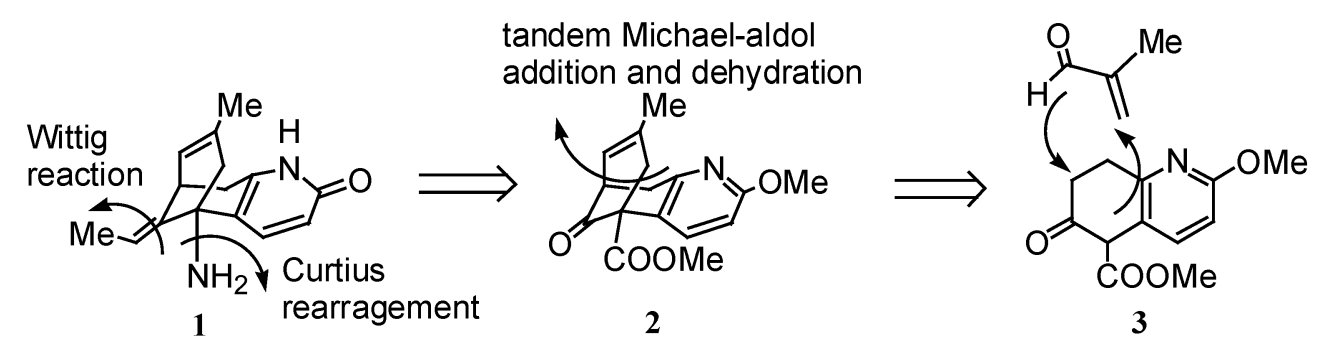

Scheme 1

The $\beta$-keto ester functionalities in key intermediate $\mathbf{3}$ would provide not only an activating group for the construction of three-carbon bridged compound $\mathbf{2}$ by tandem Michael-aldol reaction of $\mathbf{3}$ and methacrolein, but also the latent groups for the formation of both ethylidene substitution by Wittig reaction and amino group via Curtius rearrangement of the acid from ester 3. Endocyclic double bond may be formed by dehydration of the aldol product. The pyridone ring could be protected as a stable 
methoxy pyridine. Based on the synthetic strategy in Scheme 1, the total synthesis of racemic and natural (-)-HupA have been accomplished by several groups [18-20]. The first synthesis of HupA was reported by Ji's group [21]. However, the overall yield of HupA by this approach, especially the yield of dehydration of aldol adduct, is unsatisfactory.

In preparation of the key intermediate $\mathbf{3}$, a four-step approach from readily available dimethyl 4-oxopimelate was developed. The enamine 4 was directly condensed with propynamide to give pyridone 5 with two desirable carbomethoxy side chains. After O-methylation, Dieckmann condensation of diester $\mathbf{6}$ gave 3 in $39 \%$ overall yield (Scheme 2) [22-24].

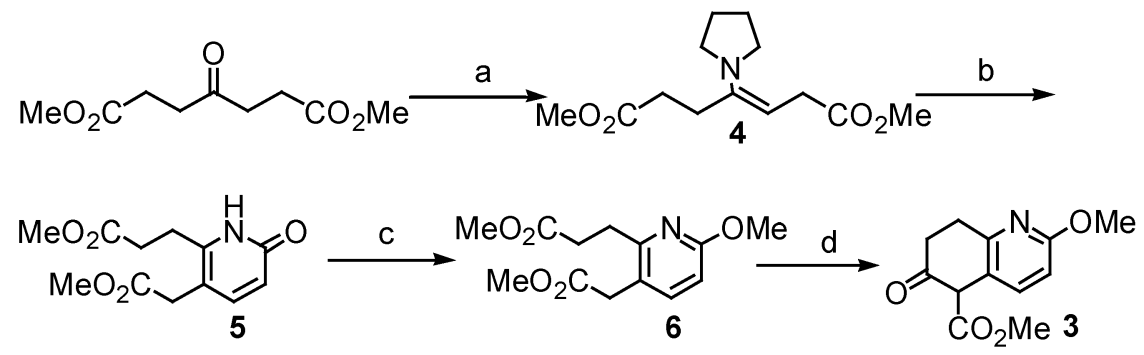

Reagents and conditions: a) pyrrolidine, $\mathrm{TiCl}_{4}$, benzene; b) $\mathrm{CH} \equiv \mathrm{CCONH}_{2}$, $\mathrm{THF}$; c) $\mathrm{Ag}_{2} \mathrm{CO}_{3}$, Mel; d) $\mathrm{NaH}$.

\section{Scheme 2}

In order to avoid the low-yielding step of elimination of the aldol product, the palladium-catalyzed bicycloannulation of $\beta$-keto ester $\mathbf{3}$ was reported by Kozikowski's group [25] using tetramethylguanidine as base and 2-methylene-1,3-propanediol diacetate as bis-electrophile in the presence of tetrakis (triphenylphosphine)-palladium(0). The resulting methylene-bridged compound 7 was in $92 \%$ yield. The double-bond migration was pursued with triflic acid, affording endocyclic olefine 9 in $90 \%$ yield. Since the double-bond migration could be performed in the last step, an isomer $\mathbf{8}$ was obtained. The overall yield of HupA was $40 \%$ from $\beta$-keto ester $\mathbf{3}$ (Scheme 3) [25].

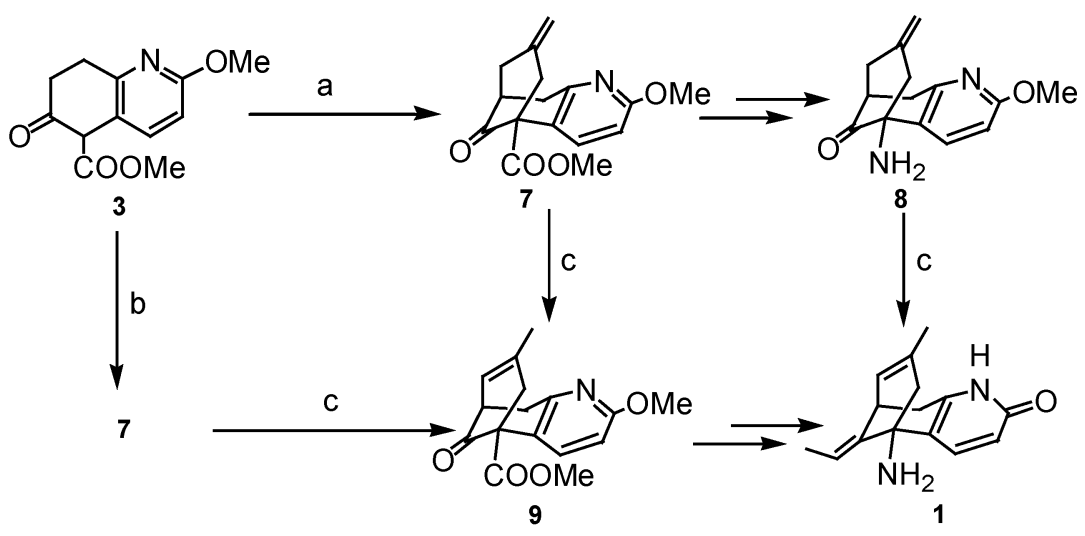

Reagents and conditions: a) 2-methylene-1,3-propanediol diacetate, $\mathrm{Pd}(\mathrm{OAc})_{2}$, $\left.\mathrm{PPh}_{3}, \mathrm{TMG} ; \mathrm{b}\right)$ 2-methylene-1,3-propanediol diacetate, ( $\mathrm{h}^{3}$-allyl)PdCl, TMG ,chiral ligand, toluene; c) triflic acid.

Scheme 3 
Based on the same stratagy, the stereoselective synthesis of HupA was tested by using different chiral ligands instead of triphenylphosphine. Terashima's group reported that the bridged compound 7 obtained by stereoselective bicycloannulation was in $64 \%$ ee using ferrocenylphosphine $(R, S)-\mathbf{1 0}$ as the chiral ligand [26].

It is expected that fine-tuning of the size of the $\mathrm{N}$-substituents of ligand $\mathbf{1 0}$ with an appropriate $\omega$-hydroxy chain would induce a favorable effect on the enantioselectivity of the reaction. Therefore, a number of chiral bis(diphenylphosphino)ferrocenyl ligands $\mathbf{1 1}$ and $\mathbf{1 2}$ were designed, synthesized, and tested for the stereoselective allylic bicycloannulation of $\beta$-keto ester $\mathbf{3}$ with 2-methylene-1, 3-propanediol diacetate. It seems that for the better stereoselectivity of the reaction induced by the chiral ligands 11 and 12, the $\mathrm{R}^{1}$ alkyl group should be bigger than propyl, and $\mathrm{R}^{2}$ should be an $\omega$-hydroxypentyl group.

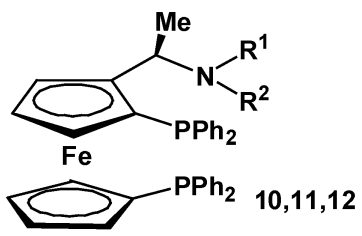

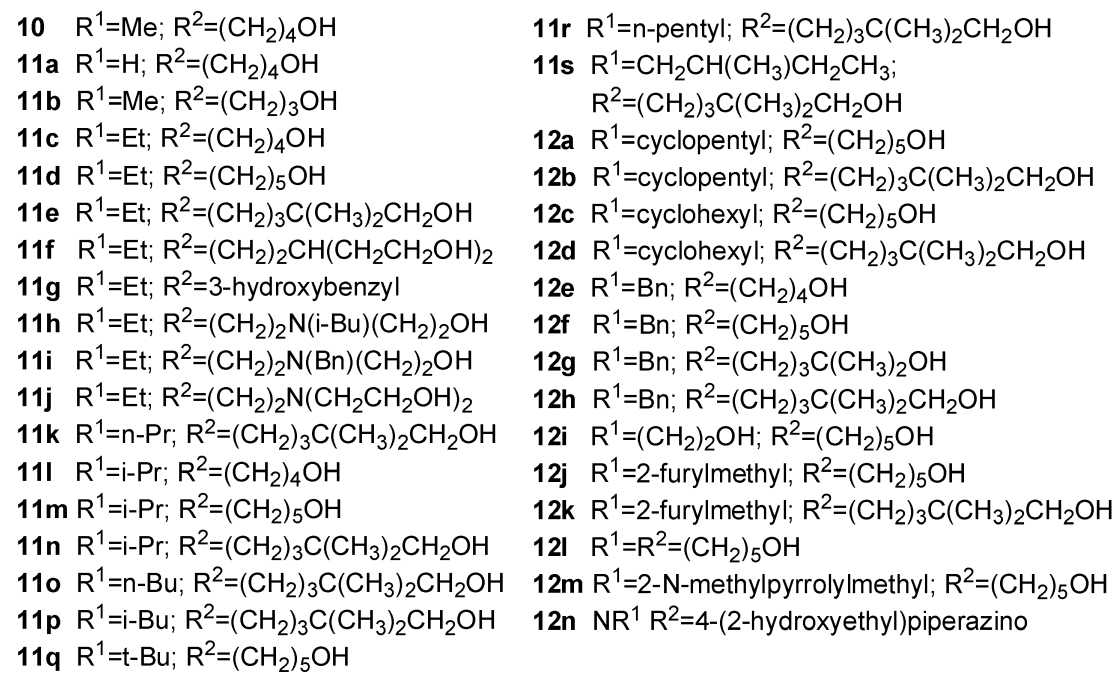

To our delight, a $90 \%$ ee of the bridged compound 7 was obtained by using $(R, S)$-ferrocenylphosphine 12a and 12b as chiral ligands. With the most efficient chiral ligands 12a and 12b in hand, the chiral nonracemic product 7 was obtained in the desired configuration for the synthesis of natural (-)-HupA (Scheme 3). Consequently, (+)-HupA could also be obtained by $(S, R)$-12a or 12b as the chiral ligand for the reaction [27-29].

\section{Analogs and derivatives of HupA}

Many analogs and derivatives of HupA were prepared and tested for their inhibitory activities of AChE. Unfortunately, neither the structurally simplified analogs nor the derivatives from the natural HupA exhibited the anti-AChE potency as HupA itself except 10-methyl HupA and a few of the Schiff bases of (-)-HupA [19,20,30]. 
ZT-1 is a Schiff base of HupA and 5-chloro-2-hydroxy-3-methoxybenzaldehyde. As a prodrug, it is hydrolyzed nonenzymatically into the active compound HupA. In vitro, the AChE inhibitory activities of ZT-1 and HupA are in the same range. In vivo, a marked dose-dependent inhibition of AChE in brain by ZT-1 was observed in rats, and it was similar to HupA. A study in monkeys showed that ZT-1 reversed the memory deficits induced by scopolamine in young adult and aged monkeys. Phase I clinical studies demonstrated it was safe and well tolerated. The oral bioavailability of ZT-1 was better than HupA. Phase II clinical trials for efficacy assessment in mild and moderate AD patients is now underway in Europe [31].

\section{HUPERZINE B}

Huperzine B (HupB, 13), the minor alkaloid in the plant $H$. serrata, is less potent and selective in the inhibition of AChE than HupA. However, it exhibited a higher therapeutic index. In behavioral studies, HupB improved memory retention and memory retrieval in adult and aged mice, and reversed the disruption of memory retention induced by scopolamine, sodium nitrite, electroconvulsive shock, and cycloheximide in mice. Recent studies also indicated that HupB had neuroprotective effect by attenuating hydrogen peroxide-induced injury [32-34].

The first synthesis of ( \pm )-HupB was accomplished by Bai's group [35]. The synthetic approach to HupB is straightforward and especially efficient in regard to the construction of the tetracyclic ring skeleton via a tandem Michael addition and intramolecular Mannich cyclization. This approach can also serve in the preparation of analogs of HupB.

\section{Bis- and bifunctional HupB compounds}

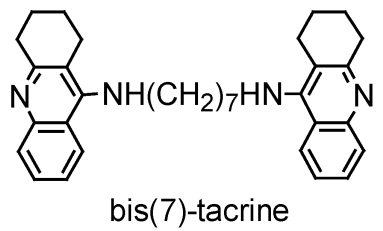

Based on the homodimer and heterodimer strategy in drug design, Pang et al. [36,37] reported that bis(7)-tacrine, the heptylene-linked tacrine dimer, possessed both optimal AChE inhibitory potency and selectivity than tacrine itself. Recent studies suggest that AChE inhibitors may simultaneously alleviate cognitive deficits and behave as disease-modifying agents by inhibiting the $\beta$-amyloid aggregation through binding to both central catalytic and peripheral active sites of AChE [38].

It is supposed that a linking chain bearing nitrogen atoms in dimers may favorably interact via cation- $\pi$-electron hydrogen bonds with some of the aromatic residues in the active gorge of AChE. The structure-activity relationship (SAR) studies reveal that all O-substituted derivatives of HupA are inactive in AChE inhibition. The X-ray analysis of TcAChE-(-)-HupB complex has also demonstrated that pyridone moiety in HupB is responsible for the key interaction with the catalytic site of the enzyme via hydrogen bonding [39]. Therefore, a series of bis-HupB and bifunctional HupB compounds, which may be able to bind both catalytic and peripheral binding sites of AChE, were thus designed and synthesized [40]. Bis-HupB compounds 14-19 are composed of two HupB moieties linked with each other on the amine nitrogen by carbon-nitrogen chains. In bifunctional HupB compounds 20, one HupB moiety of bis-HupB compounds is replaced by an aryl group. 


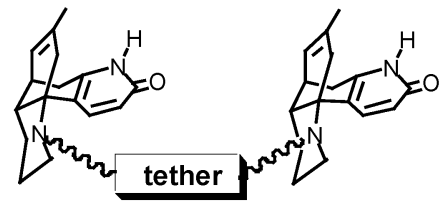

tether: $14-\mathrm{C}_{\mathrm{O}}\left(\mathrm{CH}_{2}\right)_{\mathrm{m}} \mathrm{N}_{\left(\mathrm{CH}_{2}\right)_{\mathrm{n}}^{\prime}}^{\left(\mathrm{CH}_{2}\right)_{2}} \mathrm{~N}_{\mathrm{O}}\left(\mathrm{CH}_{2}\right)_{\mathrm{m}} \mathrm{C}-$

a: $m=1, n=2$

b: $m=1, n=3$

c: $m=2, n=2$

d: $m=2, n=3$

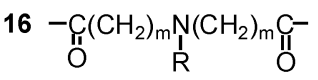

a: $m=1, R=$ cyclopropy

b: $m=1, R=$ propyl

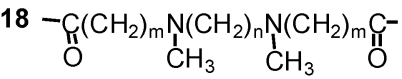

a: $m=1, n=2 \quad$ f: $m=2, n=6$

b: $m=1, n=3 \quad$ g: $m=2, n=8$

c: $m=1, n=6 \quad h: m=2, n=10$

d: $m=1, n=8 \quad$ i: $m=2, n=12$

e: $m=1, n=12$

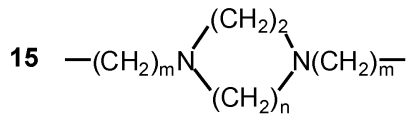

a: $m=2, n=2$

b: $m=2, n=3$

c: $m=3, n=2$

d: $m=3, n=3$

17

$-\left(\mathrm{CH}_{2}\right)_{m_{l}}\left(\mathrm{CH}_{2}\right)-$

a: $m=2, R=$ cyclopropyl

b: $m=2, R=p r o p y l$

19

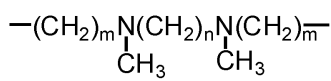

a: $m=2, n=2$ e: $m=3, n=6$

b: $m=2, n=3 \quad$ f: $m=3, n=8$

c: $m=2, n=6 \quad$ g: $m=3, n=10$

d: $m=2, n=8$
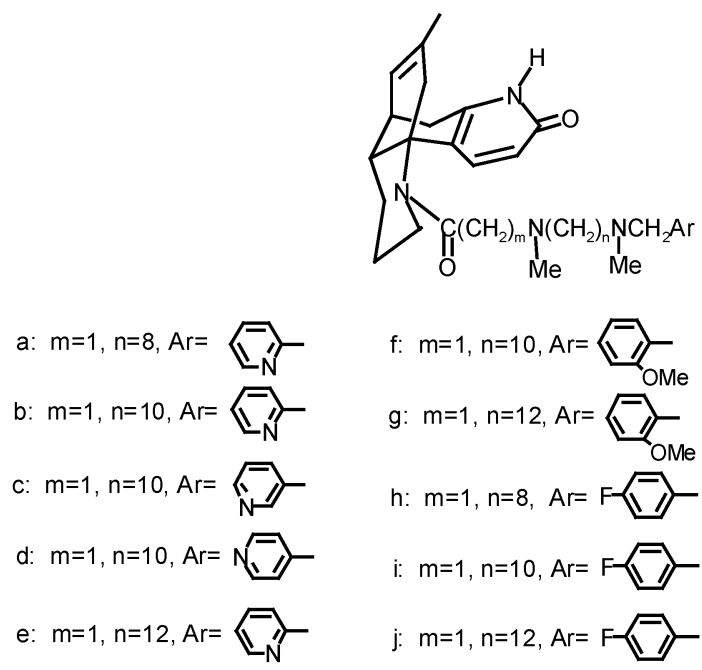

$\mathrm{k}: \mathrm{m}=2, \mathrm{n}=12, \mathrm{Ar}=\mathrm{F}$

I: $m=1, n=6, A r=$

m: m=1,n=10, Ar=

For the preparation of bis-HupB compounds, HupB was first acylated with chloroacetyl chloride or acryloyl chloride to afford chloroacetyl HupB 21 (96\% yield) and acryloyl HupB 22 (95\% yield), respectively. Reaction of piperazine, homopiperazine, cyclopropyl amine, propylamine, or $\alpha, \omega-N, N$-dimethylalkanediamines with chloroacetyl HupB 21 proceeded smoothly in acetonitrile in the presence of potassium carbonate and potassium iodide, affording bis-HupB 14a, 14b, 16a, 16b, and 18a-e, respectively. Michael addition of acryloyl HupB 22 and the corresponding amines mentioned above was conducted in acetonitrile, catalyzed by silica gel, furnishing bis-HupB 14c, 14d, and 18f-I, respectively (Scheme 4). Reduction of 14, 16, and 18 with LAH gave the reduced bis-HupB 15, 17, and 19, respectively $[40,41]$. 


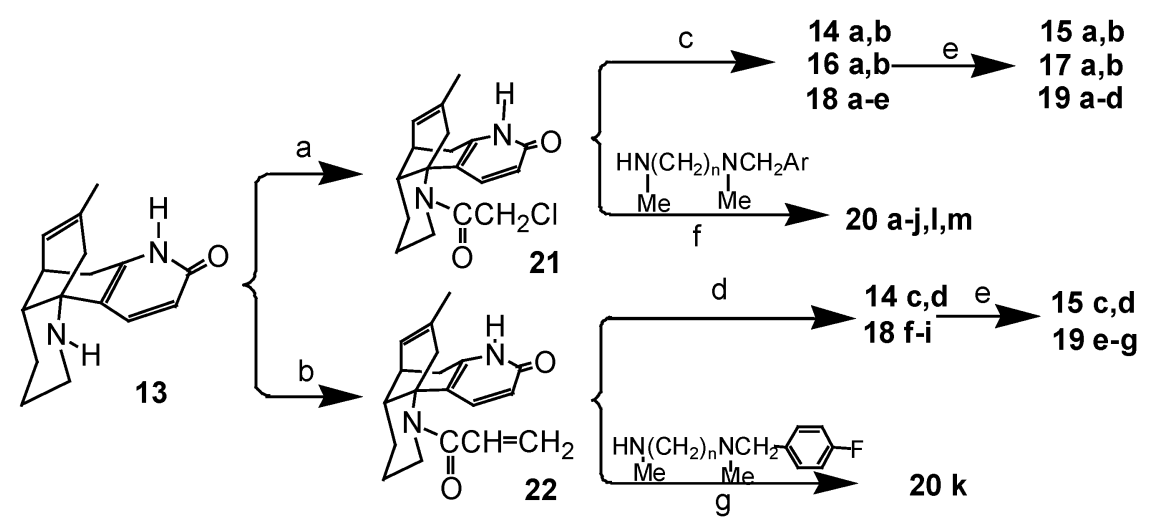

Reagents and conditions: a) chloroacetyl chloride, $\mathrm{Et}_{3} \mathrm{~N}, \mathrm{CH}_{2} \mathrm{Cl}_{2}, 0^{\circ} \mathrm{C}, 1 \mathrm{~h}, 96 \%$; b) acryloyl chloride, $\mathrm{Et}_{3} \mathrm{~N}, \mathrm{CH}_{2} \mathrm{Cl}_{2}, 0^{\circ} \mathrm{C}, 0.5 \mathrm{~h} ; \mathrm{NH}_{3}-\mathrm{CH}_{3} \mathrm{OH}, \mathrm{rt}, 12 \mathrm{~h}, 95 \%$; c) amine, $\mathrm{K}_{2} \mathrm{CO}_{3}, \mathrm{KI}, \mathrm{CH}_{3} \mathrm{CN}, 70{ }^{\circ} \mathrm{C}, 8 \mathrm{~h}, 50-90 \%$; d) amine, silica gel, $\mathrm{CH}_{3} \mathrm{CN}$, reflux, $12-24$ h, 80-98 \%; e) LAH, THF, reflux $2 \mathrm{~h}, 30-60 \%$ f) $\mathrm{K}_{2} \mathrm{CO}_{3}, \mathrm{KI}, \mathrm{CH}_{3} \mathrm{CN}, 70{ }^{\circ} \mathrm{C}, 8 \mathrm{~h}, 41-$ $88 \%$; g) silica gel, $\mathrm{CH}_{3} \mathrm{CN}$, reflux, $48 \%$.

\section{Scheme 4}

In the preparation of bifunctional HupB compounds, $\alpha, \omega-N, N^{\prime}$-dimethylalkanediamines were first alkylated with arylmethyl chloride, giving $N, N^{\prime}$-dimethyl- $N$-arylmethylalkanediamines. Reaction of $N, N^{\prime}$-dimethyl- $N$-arylmethylalkanediamines with chloroacetyl HupB 21 or acryloyl HupB 22 furnished bifunctional HupB compounds 20 (Scheme 4) [41].

All the bis- and bifunctional HupB compounds were tested for their ChE inhibition and selectivity for AChE. In bis-HupB compounds, the most potent one is bis(18)-HupB (18h), and in bifunctional HupB compounds, the most potent is bifunctional(15)-HupB (20f) (Table 1).

Table $1 \mathrm{ChE}$ inhibition and selectivity of bis- and bifunctional HupB compounds. $^{\mathrm{a}}$

\begin{tabular}{lcccc}
\hline Compounds & $\begin{array}{c}\text { Atom numbers } \\
\text { of tether }\end{array}$ & $\begin{array}{c}\mathrm{AChE} \\
\left(\mathrm{IC}_{50}, \mathrm{nM}\right)^{\mathrm{b}}\end{array}$ & $\begin{array}{c}\text { BuChE } \\
\left(\mathrm{IC}_{50}, \mu \mathrm{M}\right)^{\mathrm{c}}\end{array}$ & $\begin{array}{c}\text { Selectivity } \\
\text { for }^{\mathrm{AChE}} \mathrm{d}^{\mathrm{d}}\end{array}$ \\
\hline HupA & - & $72.4 \pm 3.8$ & $70.2 \pm 0.8$ & 970 \\
HupB & - & $19300 \pm 174$ & $228 \pm 0.6$ & 12 \\
$\mathbf{1 8 h}$ & 18 & $11.8 \pm 1.6$ & $65.0 \pm 2.3$ & 5508 \\
$\mathbf{2 0 f}$ & 15 & $21.1 \pm 1.4$ & $8.65 \pm 0.81$ & 410 \\
\hline
\end{tabular}

${ }^{\mathrm{a} A s s a y}$ performed by the modified Ellman method at $\mathrm{pH}=7.4$. Results are the mean \pm SD.

${ }^{b}$ Assay performed using rat cortex homogenate in aqueous solution.

${ }^{\mathrm{c}}$ Assay performed using rat serum.

${ }^{\mathrm{d}}$ Selectivity for $\mathrm{AChE}$ is defined as $\mathrm{IC}_{50}(\mathrm{BuChE}) / \mathrm{IC}_{50}(\mathrm{AChE})$.

In comparison with HupB, most of the bis-HupB and bifunctional HupB compounds are much more potent in the inhibition of AChE. The most potent ones, $\mathbf{1 8 h}$ and 20f, exhibited increase by three orders of magnitude in $\mathrm{AChE}$ inhibition and by two orders of magnitude in selectivity for AChE vs. BuChE than its parent HupB. The length of the tether plays a key role in the inhibition and the selectivity of AChE. The optimal length of the tethers is in a range of 15-18 atoms.

On an equimolar basis, $\mathbf{1 8 h}$ is 3 -fold more potent in AChE inhibition than donepezil in mice. No significant difference was observed in $\mathrm{AChE}$ inhibition of $\mathbf{1 8 h}$ between oral and intraperitoneal admin- 
istrations. Mice water-maze studies showed that $\mathbf{1 8 h}$ remarkably improved scopolamine- and ischemiainduced spatial performance deficits. In addition, $\mathbf{1 8 h}$ also attenuated $\beta$-amyloid and oxygen-glucose deprivation-induced cytotoxicity and oxidative stress as well as staurosporine-induced apoptosis [42].

\section{Docking studies of bis (18)-HupB (18h)}

In order to explore the possible binding conformation and interaction mode of the bis-HupB compounds with AChE, a molecular modeling study was performed, employing the docking program DOCK4.0 based on the structure of the complex of $T c$ AChE with HupB (PDB entry 1GPN). Since bis(18)-HupB $(\mathbf{1 8 h})$ afforded maximum inhibitory potency, it was selected for docking simulations. Both $\mathrm{sp}^{3} \mathrm{~N}$ atoms in $\mathbf{1 8 h}$ were treated as protonated. The central catalytic pocket, peripheral pocket, and the binding gorge were taken as the targets in the docking simulation. In the search for multiple anchors, the TcAChE structure was kept fixed and the bis(18)-HupB (18h) flexible while the maximum-orientations and configurations-per-cycle parameters were set to 600 and 150 , respectively [40].

The docking results demonstrated that one HupB moiety in $\mathbf{1 8 h}$ interacted with TcAChE in the central catalytic pocket near the residue Trp84, and another HupB moiety interacted in the peripheral pocket near the residue Trp279 (Fig. 2). The binding position and mode of the central catalytic HupB moiety is similar to HupB in the crystal structure of $T c$ AChE-HupB complex (1GPN), having two hydrogen bonds with Tyr130 and hydrophobic interaction with Trp84, Gly118, Gly119, Phe290, Phe330, Phe331, and His440. The other HupB moiety in the peripheral pocket interacted with Asn280 through a hydrogen bond, and with Trp279 and Leu282 via hydrophobic interaction. The long tether could fold with a proper conformation in the gorge that might favorably interact with Tyr70, Asp72, Tyr121, Trp279, Ile287, Phe330, and Tyr334 through hydrophobic interaction (Fig. 2). The simultaneous interactions of $\mathbf{1 8 h}$ in the central pocket, gorge passage, and peripheral pocket of $T c \mathrm{AChE}$ suggest the reason for the high inhibitory potency of AChE.

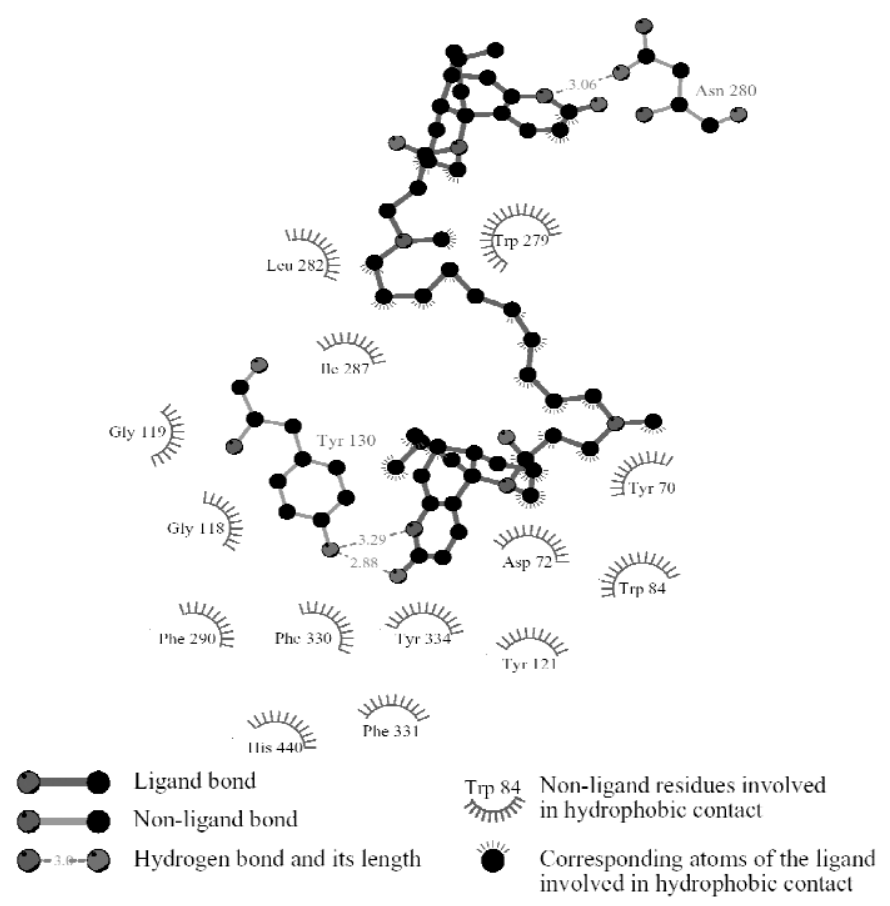

Fig. 2 Interaction between bis(18)-HupB (18h) and TcAChE. 


\section{CONCLUSIONS}

HupA has better penetration through blood-brain barrier, higher oral bioavailability, and longer duration of AChE inhibition in comparison with other well-known AChE inhibitors. Clinical trials have demonstrated that HupA produces significant improvements in memory deficits in aged and AD patients. The HupA-AChE complex has a longer life than other prophylactic sequestering agents, so HupA has now been proposed as a pretreatment drug for organophosphonates nerve agents.

In addition, HupA possesses different pharmacological actions other than the inhibition of hydrolysis of ACh. These noncholinergic roles-for instance, the antagonist effect on NMDA receptor, the protection of neuronal cells against $\beta$-amyloid, free radicals, and hypoxia-ischemia-induced injury-could be important too in AD treatment.

The therapeutic effects of HupA are probably based on a multitarget mechanism. Studies on the interactions between AChE and bis-HupB or bifunctional HupB compounds at the atomic level by molecular docking methods and X-ray crystallographic analysis are valuable for designing new ChE inhibitors with improved therapeutic profiles for $\mathrm{AD}$ treatment.

\section{ACKNOWLEDGMENTS}

The contributions of the collaborators, Profs. Jiasen Liu, Dayuan Zhu, Xican Tang, Xuchang He, Hualiang Jiang, J. L. Sussman, Ruyun Ji, and S.S. Xu, and postgraduate students whose names are mentioned in the references are deeply appreciated. We gratefully acknowledge the financial supports from National Natural Science Foundation of China (Grants 29725203, 20102007, 29725203, 20072042, 39170529, 39170860, 39770846, and 30070865), the State Key Program of Basic Research of China (Grant 2002CB512802), and the 863 Hi-Tech Program of China (Grants 2002AA233061, 2001AA235051, and 2001AA235041).

\section{REFERENCES}

1. M. S. Butler. J. Nat. Prod. 67, 2141 (2004).

2. G. A. Cordell, M. D. Colvard. J. Ethnopharmacol. 100, 14 (2005).

3. I. Raskin, D. M. Ribnicky, S. Komarnytsky, N. Ilic, A. Poulev, N. Borisjuk, A. Brinker, D. A. Moreno, C. Ripoll, N. Yakoby, J. M. O’Neal, T. Cornwell, I. Postor, B. Fridlender. Trends Biotechnol. 20, 522 (2002).

4. J. S. Liu, C. M. Yu, Y. Z. Zhou, Y. Y. Han, F. W. Wu, B. F. Qi, Y. L. Zhu. Acta Chim. Sin. 44, 1035 (1986).

5. J. S. Liu, Y. L. Zhu, C. M. Yu, Y. Z. Zhou, Y. Y. Han, F. W. Wu, B. F. Qi. Can. J. Chem. 64, 837 (1986).

6. C. M. Yu, X. C. Tang, J. S. Liu. U.S. Patent 5,177,082, Jan. 5, 1993.

7. X. Q. Ma, C. H. Tan, D. Y. Zhu, D. R. Gang. J. Agric. Food Chem. 53, 1393 (2005).

8. X. Q. Ma, C. H. Tan, D. Y. Zhu, D. R. Gang. J. Ethnopharmacol. 104, 54 (2006).

9. X. Q. Ma, D. R. Gang. Nat. Prod. Rep. 21, 752 (2004).

10. D. H. Cheng, X. C. Tang. Pharmacol., Biochem. Behav. 60, 377 (1998).

11. H. Wang, X. C. Tang. Acta Pharmacol. Sin. 19, 27 (1998).

12. Y. Q. Liang, X. C. Tang. Neurosci. Lett. 361, 56 (2004).

13. Z. Q. Xiong, D. H. Cheng, X. C. Tang. Acta Pharmacol. Sin. 19, 128 (1998).

14. L. Y. Ou, X. C. Tang, J. X. Cai. Eur. J. Pharmacol. 433, 151 (2001).

15. T. Wang, X. C. Tang. Eur. J. Pharmacol. 349, 137 (1998).

16. R. Wang, H. Yan, X. C. Tang. Acta Pharmacol. Sin. 27, 1 (2006) and refs. cited therein.

17. Q. Q. Sun, S. S. Xu, J. L. Pan, H. M. Guo, W. Q. Cao. Acta Pharmacol. Sin. 20, 601 (1999). 
18. D. L. Bai, Z. F. Wang, S. Feng, X. C. Tang. In Advances in Pharmaceutical Chemistry, D. L. Bai, K. X. Chen (Eds.), pp. 378-383, Chemical Industry Press, Beijing (2005).

19. D. L. Bai, X. C. Tang, X. C. He. Curr. Med. Chem. 7, 355 (2000) and refs. cited therein.

20. H. L. Jiang, X. M. Luo, D. L. Bai. Curr. Med. Chem. 10, 2231 (2003).

21. L. G. Qian, R. Y. Ji. Tetrahedron Lett. 30, 2089 (1989).

22. W. P. Chen, F. Q. Yang. Chin. J. Med. Chem. 2, 34 (1992).

23. S. Feng, X. C. He, G. L. Yu, Y. Xia, D. L. Bai. Org. Prep. Proc. Int. 36, 129 (2004).

24. L. G. Qian, K. J. Gu, R. Y. Ji. Chin. J. Med. Chem. 2, 1 (1992).

25. G. Campiani, L. Q. Sun, A. P. Kozikowski, P. Aagaard, M. McKinney. J. Org. Chem. 58, 7660 (1993).

26. S. Kaneko, T. Yoshino, T. Katoh, S. Terashima. Tetrahedron Lett. 54, 5471 (1998).

27. X. C. He, B. Wang, D. L. Bai. Tetrahedron Lett. 39, 411 (1998).

28. X. C. He, B. Wang, G. L. Yu, D. L. Bai. Tetrahedron: Asymmetry 12, 3213 (2001).

29. D. L. Bai, et al. To be published.

30. A. P. Kozikowski, W. Tuckmantel. Acc. Chem. Res. 32, 641 (1999).

31. D. Y. Zhu, C. H. Tan, Y. M. Li. In Medicinal Chemistry of Bioactive Natural Products, X. T. Liang, W. S. Fang (Eds.), pp. 143-182, Wiley-Interscience, Hoboken, NJ (2006).

32. J. Liu, H. Y. Zhang, L. M. Wang, X. C. Tang. Acta Pharmacol. Sin. 20, 1415 (1999).

33. H. Y. Zhang, X. C. Tang. Neurosci. Lett. 292, 41 (2000).

34. Z. F. Wang, J. Zhou, X. C. Tang. Acta Pharmacol. Sin. 23, 1193 (2002).

35. B. G. Wu, D. L. Bai. J. Org. Chem. 62, 5978 (1997).

36. Y. P. Pang, P. Quiram, T. Jelacic, F. Hong, S. Brimijoin. J. Biol. Chem. 271, 23646 (1996).

37. P. R. Carlier, Y. F. Han, E. S. H. Chow, C. P. L. Li, H. Wang, T. X. Lieu, H. S. Wong, Y. P. Pang. Bioorg. Med. Chem. 7, 351 (1999).

38. P. Munoz-Ruiz, L. Rubio, E. Garcia-Palomero, I. Dorronsoro, M. Monte-Millan, R. Valenzuela, P. Usan, C. Austria, M. Bartolini, V. Andrisano, A. Bidon-Chanal, M. Orozco, F. Javier Luque, M. Medina, A. Martinez. J. Med. Chem. 48, 7223 (2005) and refs. cited therein.

39. H. Dvir, H. L. Jiang, D. M. Wong, M. Harel, M. Chetrit, X. C. He, G. Y. Jin, G. L. Yu, X. C. Tang, I. Silman, D. L. Bai, J. L. Sussman. Biochemistry 41, 10810 (2002).

40. S. Feng, Z. F. Wang, X. C. He, S. X. Zheng, Y. Xia, H. L. Jiang, X. C. Tang, D. L. Bai. J. Med. Chem. 48, 655 (2005).

41. S. Feng, Y. Xia, D. M. Han, C. Y. Zhang, X. C. He, X. C. Tang, D. L. Bai. Bioorg. Med. Chem. Lett. 15, 523 (2005).

42. X. C. Tang, et al. To be published. 